\title{
A DESISTÊNCIA DE ESTUDANTES DE UM CURSO NA MODALIDADE A DISTÂNCIA VOLTADO PARA ADOLESCENTES
}

\author{
Andressa Sasaki Vasques Pacheco, Universidade Federal de Santa Catarina, \\ andressa.ufsc@gmail.com \\ Mauricio Rissi, Universidade Federal de Santa Catarina, mauriciorissi@cse.ufsc.br \\ Marina Keiko Nakayama, Universidade Federal de Santa Catarina, marina@egc.ufsc.br \\ Ricardo Azambuja Silveira, Universidade Federal de Santa Catarina, silveira@inf.ufsc.br \\ Fernando José Spanhol, Universidade Federal de Santa Catarina, spanhol@led.ufsc.br
}

\section{RESUMO}

O Projeto Aluno Integrado no ano de 2010 conta com a participação de setenta mil estudantes de escola públicas em todo Brasil. Esta pesquisa objetiva analisar a desistência dos estudantes dos Estados gerenciados pela UFSC. Quanto aos procedimentos metodológicos classifica-se como descritiva, predominantemente qualitativa, estudo de caso e documental. Como resultados, pode-se avaliar que os estudantes mais jovens tiverem menor desistência. Além disso, houve maior desistência no Estado do Rio Grande do Sul. Os principais problemas detectados foram seleção dos estudantes, capacitação presencial, falta de acesso a computadores e internet, problemas na plataforma, falta de interesse no curso e o não conhecimento da modalidade a distância.

Palavras-chave: Educação a distância. Desistência. Adolescente.

\section{ABSTRACT}

The Project Pupil Integrated in the year of 2010 counts on the participation of seventy thousand public school pupils in all Brazil. This objective research to analyze the students desistance. About the methodological procedures it is classified as: descriptive, predominantly qualitative, case study. As results, it can be evaluated that the student youngest will have minor desistance. Moreover, it had greater desistance in the State of the Rio Grande Do Sul. The main detected problems had been: election of the students, actual qualification, lack of access the computers and Internet, problems in the platform, lack of interest in the course, not knowledge of the distance modality.

Word-key: Distance Education. Desistance. Adolescent.

\section{INTRODUÇÃO}

É imprescindível ter consciência de que não basta somente a introdução de computadores e novas tecnologias para trazer mudanças na aprendizagem (GARCIA, 1997). Essas são ferramentas que auxiliam na melhoria da aprendizagem, mas torna-se necessário que se repense em novos modelos metodológicos e em uma aprendizagem onde haja espaço para a construção do conhecimento. Nevado (1997) complementa que conhecer é integrar a informação no nosso referencial, no nosso paradigma, apropriando, tornando-a significativa para nós. O conhecimento não se passa, se constrói.

Esse aumento de informações e TIC's, bem como de caminhos para o aprendizado gerou novas oportunidades de como as pessoas podem aprender e adquirir conhecimentos (ANOHINA, 2005). A autora complementa ainda que várias são as expressões para delimitar 
essa modalidade de ensino mediada por tecnologias, sendo que este trabalho utilizará a expressão Educação a distância - EaD.

A EaD é caracterizada por separação entre professor e estudante, autonomia do estudante, uso de tecnologias para compartilhamento de material e comunicação de mão dupla entre os agentes (PAULSEN, 2002).

Desta forma, a modalidade de educação a distância foi potencializada, culminando em uma educação cada vez mais próxima e personalizada, além de privilegiar a troca de conhecimentos em rede e, com isso, instigar o surgimento de comunidades de aprendizagem (ABRAEAD, 2007).

Um dos problemas enfrentados pelos gestores de cursos é a evasão nessas instituições. A UNESCO (1997) destaca que em muitos países ainda há acesso limitado ao ensino e altas taxas de evasão escolar.

Nesta perspectiva faz-se importante verificar os fatores contribuintes à evasão e as dificuldades dos estudantes freqüentes, com o intuito de minimizar o número dos acadêmicos que abandonam o curso, o que poderia levar o curso a realizar uma avaliação constante (BIAZUS, 2004).

A evasão tem se caracterizado como uma realidade recorrente no âmbito do ensino, em várias partes do mundo. As formas de acesso e permanência dos estudantes têm preocupado pesquisadores e gestores no mundo inteiro (FARIA, ALCANTARA, GOIA, 2008).

Em pesquisa anterior pôde-se perceber que muitos dos fatores citados como dificultadores e contribuintes à evasão advêm de uma carência oriunda de um modelo mental da modalidade presencial, ou seja, fatores como a falta de contato direto com professores, colegas e tutores, que acabam por trazer dificuldades aos estudantes, podendo assim levá-los ao abandono do curso. Para tanto, faz-se necessário uma gestão mais ativa de atividades presenciais e utilização de recursos que permitam atividades em grupo entre os estudantes, para que os mesmos não se sintam sozinhos e desmotivados (PACHECO, 2007).

Para Cislaghi (2008) o estudo do fenômeno da evasão discente em IES brasileiras ainda é uma área de pesquisa a ser desenvolvida e que, certamente, esse estágio inicial de conhecimento tem relação direta com a pouca atenção que é dada ao setor da educação.

Neste contexto tem-se o Projeto Aluno Integrado, o qual faz parte do Programa Nacional de Formação Continuada em Tecnologia Educacional (Proinfo Integrado), do governo Federal.

O objetivo do Proinfo Integrado é promover o uso pedagógico das Tecnologias de Informação e Comunicação nas redes públicas de educação básica. O programa leva às escolas computadores, recursos digitais e conteúdos educacionais. Em contrapartida, estados, Distrito Federal e municípios devem garantir a estrutura adequada para receber os laboratórios e capacitar os estudantes e professores para uso das máquinas e tecnologias.

O Aluno Integrado tem como tema central educação e tecnologia para um mundo melhor, buscando explorar diferentes perspectivas dentro desse tema em todas as etapas da educação básica. Assim, os estudantes desse curso tem a capacitação em relação a educação a distância, hardware, sistemas operacionais e manutenção de computadores.

Desta forma, esta pesquisa tem como objetivo analisar as desistências dos estudantes do projeto Aluno Integrado gerenciado pela UFSC.

\section{EVASÃO NA EDUCAÇÃO A DISTÂNCIA}

Inicialmente, resgata-se os conceitos norteadores desta pesquisa quanto à evasão e EaD. A evasão definitiva é a saída definitiva da universidade, ou seja, é aquela pela qual o estudante se afasta da instituição, por abandono, desistência definitiva do curso ou 
transferência para outra universidade. Já educação a distância é a educação formal, baseada em uma instituição na qual o grupo de aprendizagem se separa e na qual se utilizam sistemas de telecomunicações interativos para conectar estudantes, recursos e instrutores (SIMONSON, 2006).

Em complemento considera-se evasão a desistência do curso, incluindo os que, após terem se matriculado, nunca se apresentaram ou se manifestaram de alguma forma para os colegas e mediadores do curso, em qualquer momento (FÁVERO; FRANCO, 2006). Outro conceito é apresentado por Maia e Meirelles (2005), para os quais a evasão dos cursos consiste em estudantes que não completam cursos ou programas de estudo, podendo ser considerado como evasão aqueles estudantes que se matriculam e desistem antes mesmo de iniciar o curso.

Na modalidade a distância, conforme Rumble (2003), em geral as taxas de conclusão são bastantes baixas e os índices de evasão altos, mas a comparação entre os índices das IES é prejudicado pelos diferentes cálculos aplicados. Para algumas IES, são contabilizados como estudantes regulares somente aqueles que após a matrícula freqüentam pelo menos dois meses de curso, ou seja, os estudantes que apenas se matriculam e os que só participam das aulas por um período inferior a esse não são inclusos como estudantes dessas IES, não sendo contabilizados assim como estudantes evadidos das mesmas. Como exemplo pode-se citar a British Open University, a qual elimina aqueles que não seguem o curso regularmente e só matriculam novos estudantes após dois ou três meses de freqüência.

Aretio (1987) corrobora com esta visão, afirmando que muitos simplesmente se matriculam sem chegar a realmente participar do curso. Por isso, algumas instituições só contabilizam os estudantes que se apresentam aos exames. Estes índices, comparados com os da universidade convencional, são mais aproximados e mais reais.

Complementa ainda que nas instituições a distância, muitos dos estudantes se matriculam, adquirem o material didático obrigatório e nada mais se volta a saber deles. Estes estudantes abandonam o curso sem ter provado sua capacidade ou o alcance de sua possível dedicação ao estudo, ao menos sem que isso conste. Um aviso para a detecção de um possível estudante a evadir do curso é o não cumprimento de alguma prova ou exame das matérias (ARETIO, 2002).

Portanto, de acordo com Aretio (2002), tem-se dois tipos de abandonos em EaD: abandono sem começar e abandono real. Fala-se de abandono sem começar quando refere-se a aqueles estudantes dos quais não existe registro avaliador algum mesmo tendo estado matriculados um ou mais anos. Abandono real seria aquele em que os estudantes que chegam a ter um registro de avaliação e depois abandonam sem terminar os estudos. Este tipo de abandono vem sendo mais próximo, em porcentagem, ao dos cursos presenciais.

Quanto à análise de algumas pesquisas em EaD, Aretio (1987) apresenta o estudo desenvolvido por Woodley e Mclntosh, os quais objetivaram levantar os motivos para a não realização da matrícula definitiva (depois do $1^{\circ}$ ano) nos cursos que os estudantes estavam interessados . Dentre os motivos apontados, $77 \%$ estavam relacionados a problemas de caráter familiar e situações de trabalho; $21 \%$ referiram-se a problemas causados pela forma e o conteúdo dos cursos e $2 \%$ por motivos de caráter administrativo.

Já o estudo realizado por Tannous e Ropoli (2005) em cursos de extensão da Unicamp (Universidade Estadual de Campinas), apresentou os seguintes índices de evasão: o primeiro curso oferecido contou com a participação de doze inscritos, dos quais cinco desistiram (índice de evasão $=41,7 \%$ ), o segundo curso estiveram presentes onze inscritos, dos quais seis desistiram (índice de evasão $=54,5 \%$ ), o terceiro curso houve oito inscritos, dos quais quatro desistiram (índice de evasão $=50 \%$ ).

Já Fozdar, Kumar e Kannan (2006) relatam sobre a evasão na Indira Gandhi National Open University, na Índia. Procurou-se determinar as razões da evasão, chegando ao resultado 
de nove fatores. Assim, foram delineadas sugestões de melhorias para a redução da evasão nesta universidade.

Morgan e Mckenzie (2003) defendem em seu estudo uma maior autonomia dos estudantes. Ressaltam que todos têm problemas, não só os estudantes, mas estes precisam ser autônomos e independentes para resolver o que for necessário, ou seja, que sejam pró-ativos e não dependam sempre de tutores ou professores.

Complementa-se ainda com a pesquisa de Rovai (2002), o qual argumenta que os cursos a distância precisam criar mais senso de comunidade entre os estudantes, a fim de minimizar problemas e o sentimento de solidão desse estudante.

Abdo, Ninomiya e Raab (2007) mostram uma experiência de EaD no Camboja, sendo que um dos problemas era o de como os estudantes entravam no curso e sua pouca habilidade com tecnologias. Assim, foi feito um projeto para preparar os estudantes antes dos cursos, para que os mesmos se adaptem às tecnologias e desenvolvem competências essenciais para a realização dos mesmos, minimizando assim os níveis de evasão.

Uma crítica feita por Ludwig-Hardman e Dunlap (2003) diz respeito ao programa de retenção de estudantes, mostrando que muitos não são adequados às instituições e aos problemas dos estudantes.

Já Filkins, Kehoe e Mclaughlin, (2001) relatam sete princípios de práticas para EaD: encorajar o contato entre estudantes e a instituição, desenvolver reprocidade e cooperação entre estudantes, utilizar ativamente técnicas de aprendizado, dar feedback aos estudantes, enfatizar trabalhos em equipe, comunicar as expectativas, respeitar os diferentes talentos e formas de aprendizagem.

Quanto ao cenário nacional, a pesquisa do Anuário Brasileiro Estatístico de Educação Aberta e a Distância - ABRAEAD - (2007) aponta algumas informações sobre a Evasão em $\mathrm{EaD}$ no Brasil. Quanto aos fatores que influenciam na evasão desses estudantes destacam-se: a falta de tempo e a situação financeira. Outra informação importante aponta que nos cursos de graduação, $96 \%$ da evasão ocorre nos primeiros semestres do curso, o que mostra a importância de pesquisas sobre a evasão dos estudantes desde o começo do curso.

Já Fávero e Franco (2006) apresentam uma pesquisa realizada pela FGV-EAESP Escola de Administração de Empresas de São Paulo da Fundação Getúlio Vargas, em 2005, sobre o índice de evasão em educação superior a distância, alcançando-se os seguintes resultados:

a) os cursos totalmente a distância têm maior evasão (30\%) que os cursos semipresenciais $(8 \%)$;

b) os cursos de extensão e especialização têm $25 \%$ de evasão;

c) enquanto nas públicas ocorre $11 \%$ de evasão, nas privadas o percentual é de $23 \%$;

d) a maior diferença existente está entre os cursos certificados pelo MEC (21\%) e os cursos com certificação própria (62\%). Este percentual de $62 \%$ de evasão em cursos com certificação própria pode indicar que existe pouca credibilidade e confiabilidade nesta certificação, uma vez que, se o certificado for emitido pelo MEC, este índice cai para $21 \%$.

Para Maia e Meirelles (2005), um dos fortes fatores que influenciam a evasão é o fato de o curso ser distribuído totalmente a distância, podendo ocasionar que os estudantes sintamse desestimulados a se manterem cursando por não se considerarem integrantes de uma turma. Os autores ressaltam que este é um forte traço cultural, o de encontrar pessoalmente o professor e ter aula presencial. Quando isso ocorre, o estudante se sente como participante de um grupo e mais disposto a interagir a distância, não abandonando o curso.

Outros fatores analisados por Maia e Meirelles (2005), são os Ambientes Virtuais de Ensino e Aprendizagem (AVEA) e a forma de desenho do curso. O desenho do curso relaciona-se à forma como o curso está estruturado considerando a tecnologia computacional, 
sendo as principais a videoconferência, a teleconferência, a internet e o CD-ROM. Dessa maneira, destacam que o índice de evasão mantém relação com a tecnologia utilizada no curso a distância.

Corroborando com os autores, Fávero e Franco (2006) ressaltam também a importância de um AVEA interativo, pois os estudantes que fazem cursos a distância, na sua grande maioria, têm uma característica em comum, que é a solidão, isto é, uma sensação de abandono que os cercam durante todo o curso, principalmente quando não ocorre uma maior interação entre os atores desse processo.

Em continuidade, Maia e Meirelles (2005) destacam que o índice de evasão pode ser justificado também por variáveis exógenas ao curso a distância, como questões particulares dos estudantes.

Outra pesquisa, realizada nos cursos de extensão da Unicamp, apresenta os seguintes motivos como fatores mais relevantes para a evasão (TANNOUS; ROPOLI, 2005):

a) priorização de outras atividades profissionais não previstas no início do curso;

b) interesse apenas em conhecer as características do ambiente de EaD sem ter um projeto educacional definido;

c) falta dos pré-requisitos necessários para acompanhar o curso;

d) problemas de saúde; e

e) problemas técnicos de acesso, precisamente de conexão.

Em complemento sobre os fatores de evasão na modalidade a distância, destaca-se que se for considerado que a maioria dos estudantes é formado por adultos entre 25 e 40 anos, que trabalham e estudam, percebe-se que uma das grandes causas da evasão é o cansaço que as pessoas sentem ao final do dia, impossibilitando-as de aprender na sua totalidade, independente do local onde esteja ocorrendo a aula (FÁVERO; FRANCO, 2006).

Também cabe destacar que muitos estudantes se surpreendem com a consistência dos cursos, pois há uma sensação, geralmente frustrada, que os cursos a distância são mais fáceis que os presenciais (ABRAEAD, 2007).

Em relação às ações para minimizar a evasão em EaD, Rumble (2003) cita alguns itens, como:

a) fornecimento de excelente material pedagógico;

b) prestação de informações rápidas e corretas aos estudantes, para evitar que um estudante escolha incorretamente o curso que deseja seguir ou para o qual não esteja ainda preparado;

c) informação rápida aos estudantes e assistências àqueles que já estão no sistema, ajudando-os a superar problemas nos estudos; e

d) criação de um clima estimulante para que os estudantes busquem orientação junto aos tutores, conselheiros e mesmo com outros estudantes. Enfim, trata-se de preparar um ambiente que estimule a participação em um grupo de estudos, de forma a incentivar a motivação e o interesse.

\section{PROCEDIMENTOS METODOLÓGICOS} participante.

Caracteriza-se esta pesquisa como estudo de caso, qualitativo, descritivo e

Utilizou-se de documentos como relatórios e banco de dados do curso. Além disso, também foram utilizadas as comunicações (como e-mail e fóruns) feitas com a supervisão, orientadores, tutores e estudantes do curso.

Todos os nomes dos entrevistados são sigilosos, utilizando para efeito de divulgação da pesquisa uma codificação utilizada no projeto (tutor 1, tutor 2, etc..). Os dados referentes a 
esta pesquisa refletem os três primeiros meses do projeto Aluno Integrado, o qual tem previsão de término para 21 de novembro de 2010.

\section{RESULTADOS}

O Projeto Aluno Integrado no ano de 2010 conta com a participação de setenta mil estudantes em todo Brasil. Para o gerenciamento do curso, foram designadas três universidades: a Universidade Federal de Goiás (UFG), a Universidade Federal de Santa Catarina (UFSC) e a Universidade Federal de Ouro Preto (UFOP).

Esta pesquisa acontece no âmbito da UFSC, a qual possui 15 mil estudantes desse projeto, situados nos estados do Rio Grande do Sul, Santa Catarina, Paraná e Mato Grosso do Sul.

A equipe é formada por três professores coordenadores, duas supervisores (técnica e tutoria), equipe técnica e dez orientadores de tutoria. Além disso, tem-se 206 tutores, selecionados pela UFSC e pelas secretarias municipais e estaduais. Cada tutor é responsável por em torno de 80 estudantes.

Neste contexto, cada orientador de tutoria é responsável por vinte tutores. O papel do supervisor é auxiliar nas questões pedagógicas e de gestão, por meio do contato entre os tutores e a supervisão/coordenação. Ou seja, ele é o elo de comunicação que os tutores tem com toda a gestão do curso.

Ao final do primeiro módulo decidiu-se que os estudantes que estivessem inseridos no curso, mas que não tivessem feito nenhuma atividade seriam considerados desistente. Caso algum estudante saísse após esse período seria considerado evadido.

Apresenta-se desta forma somente a análise dos estudantes desistentes, ou seja, os que foram inseridos na plataforma mas não começaram o curso.

Tabela 1: estudantes desistentes

\begin{tabular}{c|c|c|c|c|c}
\hline SECRETARIA & $\begin{array}{c}\text { ALUNOS } \\
\text { REGULARES }\end{array}$ & $\begin{array}{c}\text { ALUNOS } \\
\text { DESISTENTES }\end{array}$ & TOTAL & $\begin{array}{c}\text { \% DE ALUNOS } \\
\text { REGULARES }\end{array}$ & $\begin{array}{c}\text { \% DE ALUNOS } \\
\text { DESISTENTES }\end{array}$ \\
\hline SEDUC/MS & 152 & 149 & 301 & $50,50 \%$ & $49,50 \%$ \\
SEDUC/PR & 5878 & 3211 & 9089 & $64,67 \%$ & $35,33 \%$ \\
SEDUC/RS & 481 & 887 & 1368 & $35,16 \%$ & $64,84 \%$ \\
SEDUC/SC & 1601 & 806 & 2407 & $66,51 \%$ & $33,49 \%$ \\
UNDIME/MS & 450 & 210 & 660 & $68,18 \%$ & $31,82 \%$ \\
UNDIME/RS & 432 & 191 & 623 & $69,34 \%$ & $30,66 \%$ \\
UNDIME/SC & 280 & 75 & 355 & $78,87 \%$ & $21,13 \%$ \\
NAO INFORMADO & 408 & 156 & 564 & $72,34 \%$ & $27,66 \%$ \\
\hline TOTAL & 9682 & 5685 & 15367 & $63,01 \%$ & $36,99 \%$ \\
\hline
\end{tabular}

Fonte: Relatório 4 - Aluno Integrado

Pode-se verificar que 36,99\% dos estudantes não iniciaram o curso. Além disso, percebe-se uma variação desse percentual por estado. Cabe destacar que essas informações foram repassadas pelos próprios tutores da turma. Os classificados como "não informado" é devido a não nomeação da secretaria no relatório. Apresenta-se a seguir os principais fatores detectados sobre estes percentuais. 
Antes do início do curso foram definidos os métodos de trabalho, preparado o início do projeto, feito as devidas capacitações, preparado o sistema de apoio e capacitado as equipes UFSC, tanto os orientadores como tutores e equipe técnica. No entanto, houve alguns problemas que merecem destaque.

É importante salientar que o estudante fez uma capacitação presencial de 8 horas e de ambientação ao E-proinfo (plataforma utilizada no curso). Nesse momento vários problemas de acesso e lentidão do sistema surgiram, sendo considerados desta forma um dos primeiros fatores a influenciar na desistência do estudante. Pode-se verificar esse problema conforme relato de um tutor.

Olha eu to ficando desesperadinha já... Meus estudantes estão me mandando mensagem falando que não conseguem achar as atividades, e hj o dia todo eu não consegui entrar em nenhuma mensagem deles, toda hora fala que o bendito do servidor está com problemas e não tem como responder, e eles vão ficar esperando a resposta na mensagem, já tentei mandar e-mail mas eles não leram, porque me perguntaram novamente a mesma coisa... Tá feia a situação por aqui, a maioria dos estudantes não está acessando, tá me dando 2 tipos de medo já. Será q amanhã vai funcionar esse negócio? (tutor 54 - 30 de julho)

O tutor 135 enfatiza ainda o impacto dessa questão no público adolescente.

A plataforma está impraticável desde segunda dá acesso somente um pouco e depois não dá mais, sabe como é adolescente eles são imediatista, isso vai desestimulando a garotada é uma pena...e daí como vai ficar aqueles prazos de postagem se eles não conseguem acessar para ler os módulos e fazer as postagens? (tutor 135 - 30 de junho)

As capacitações que deveriam acontecer nos estados, sob responsabilidade das Secretarias, foram extremamente prejudicadas, e por mais de um fator. O principal deles foi certamente a lentidão do sistema E-proinfo (que mais tarde foi justificado por um erro do MEC na configuração do servidor), os outros problemas que se deve destacar foram: "o telefone sem fio" da capacitação ("MEC/UFG" capacita "Formadores" que capacita "Tutores" que capacita "estudantes" - cabe ainda mencionar que ocorreram "formadores" capacitando outros "formadores" devido ao mal dimensionamento de "formadores"); e também um alto número de estudantes que não compareceram nas capacitações (possíveis causas: má elaboração da "lista" e falta de chamado adequado dos estudantes (da lista) para as capacitações).

As listas que chegaram à coordenação do projeto foram de baixa qualidade, devido a informações incompletas, muitos erros de digitação, turmas inteiras cadastradas com o mesmo telefone e/ou email. Em alguns casos, a seleção dos estudantes não atendeu aos critérios solicitados, como idade (mínimo de 13 anos), acesso a internet, conhecimento básico de informática e uso de e-mail.

Além disso, foram detectadas escolas inteiras com o Linux educacional 2.0 (o qual não atualiza o plugin do flash), versões do plugin do flash incompatível, escolas sem acesso a internet, escolas que não dão acesso aos estudantes por falta de responsável pelo laboratório. A fim de minimizar estes problemas iniciais, iniciou-se um processo de reuniões e capacitações com os coordenadores dos estados, bem como com os tutores.

Pode-se destacar ainda a comunicação com o estudante, falha principalmente no início devido a problema de confiabilidade de dados iniciais, pois teve-se alguns problemas para contatar os estudantes, buscando auxilio com as secretarias e as escolas nesses casos.

Para tentar auxiliar nesse fato, foi feita a implementação do uso no VOIP na rotina dos tutores. Desta forma foi disponibilizado aos tutores no segundo módulo a utilização da tecnologia VOIP. Foram feitos manuais de utilização do mesmo, mas alguns tutores continuam com dificuldades, sendo os mesmos auxiliados pela equipe técnica. 
Outro ponto interessante foi a idade dos estudantes. Antes de se iniciar esta análise acreditava-se que os estudantes mais novos tivessem um índice de desistência maior, o que não é corroborado, conforme os dados a seguir.

Tabela 2: idade dos estudantes

\begin{tabular}{|c|c|c|c|c|c|}
\hline & & & \multicolumn{2}{|c|}{ desistente } & \multirow[b]{2}{*}{ Total } \\
\hline & & & Não & $\operatorname{sim}$ & \\
\hline & \multirow[t]{2}{*}{13} & Frequência Absoluta & 426 & 181 & 607 \\
\hline & & Frequência Relativa & $70,2 \%$ & $29,8 \%$ & $100,0 \%$ \\
\hline & \multirow[t]{2}{*}{14} & Frequência Absoluta & 2290 & 1184 & 3474 \\
\hline & & Frequência Relativa & $65,9 \%$ & $34,1 \%$ & $100,0 \%$ \\
\hline & \multirow[t]{2}{*}{15} & Frequência Absoluta & 2331 & 1491 & 3822 \\
\hline & & Frequência Relativa & $61,0 \%$ & $39,0 \%$ & $100,0 \%$ \\
\hline & \multirow[t]{2}{*}{16} & Frequência Absoluta & 1875 & 1149 & 3024 \\
\hline & & Frequência Relativa & $62,0 \%$ & $38,0 \%$ & $100,0 \%$ \\
\hline & \multirow[t]{2}{*}{17} & Frequência Absoluta & 932 & 657 & 1589 \\
\hline & & Frequência Relativa & $58,7 \%$ & $41,3 \%$ & $100,0 \%$ \\
\hline \multirow{2}{*}{$\begin{array}{l}\frac{0}{0} \\
\frac{\pi}{0} \\
0\end{array}$} & \multirow[t]{2}{*}{18} & Frequência Absoluta & 305 & 273 & 578 \\
\hline & & Frequência Relativa & $52,8 \%$ & $47,2 \%$ & $100,0 \%$ \\
\hline
\end{tabular}

Fonte: dados primários

Cabe destacar que não se tinha a informação da idade de todos os estudantes. Além disso tem-se ainda estudantes mais velhos, participantes de programas de EJA (Educação de Jovens e Adultos), bem como professores. Mas para esta pesquisa buscou-se analisar a faixa etária prioritária do curso. Em relato de alguns tutores, pode-se verificar que os estudantes mais próximos de 18 anos estão com outras preocupações e interesses, como vestibular ou mesmo já exercendo algum trabalho, e desta forma deixando de fazer o curso. Destaca-se também que como o conteúdo é denso, a seleção de estudantes mais jovens foi mais rígida que a seleção dos outros estudantes, buscando-se somente aqueles que tivessem grande interesse pelo curso.

Aqui em Criciúma acontece o mesmo: muitas desistências. Os estudantes conseguiram empregos e não conciliam trabalho, escola e curso. Outros reclamam que é muita coisa para ler, outros afirmam que esperavam atividades com mais jogos com as devidas avaliações, outros estão muitos satisfeitos (tutor 149).

Como a maioria dos meus estudantes estudam no período matutino resolvi ir pessoalmente nas Unidades Escolares e, para saber o porque de muitos não terem respondido as atividades do Módulo II. As justificativas foram grandes, uns esqueceram a senha, outros muita leitura, falta de tempo, novo emprego, preguiça e, por aí vai (tutor 147).

Pode-se verificar também que muitos estudantes não tinham conhecimento de como estudar a distância. Muitos achavam que seria semi-presencial (como descrito na teoria) e os tutores "buscariam" os estudantes nas escolas para fazer as atividades. Além disso, foi percebido uma necessidade constante dos estudantes de motivação e cobrança, ou seja, o papel do tutor ficou baseado principalmente no fator motivacional e não pedagógico ou tecnológico.

Por fim, cabe destacar que para combater a evasão, a gestão do curso da UFSC decidiu tentar todas as formas possíveis para resgate dos estudantes, mesmo que tenham que fazer módulos atrasados posteriormente. Essas atitudes estão relacionadas com: ligação da coordenação do curso, contato com as secretarias, com a direção da escola, com os pais e a visita presencial do tutor. Assim, foi delimitado que até o final do curso o estudante não será 
considerado evadido, até que se tenha esgotado todas as formas possíveis de resgate do estudante.

\section{CONSIDERAÇÕES FINAIS}

Em relação as considerações finais pode-se destacar que muitos problemas foram oriundos de falta de planejamento do curso, em relação a todas as esferas envolvidas: universidades, secretarias e MEC. Mas ao longo do projeto esses problemas foram sendo solucionados, mas o efeito já teve seus resultados, neste caso 36,99\% de desistência.

Cabe destacar também a necessidade de motivação dos estudantes. Diferentemente de um público adulto (normalmente usuário da modalidade a distância), esse público jovem precisa constantemente ser cobrado, utilizando as mais diversas formas de contato (e-mail, telefone, AVEA e presencial). Além disso, percebe-se que muitos têm dificuldade em vislumbrar os benefícios desse curso a médio ou longo prazo.

Outra questão é a importância de se trabalhar o planejamento do tempo em um curso a distância. Ao se matricular em um curso dessa modalidade o estudante deve estar consciente que o mesmo demanda um certo tempo, e para isso serão necessárias abdicações e escolhas. Assim, caso o estudante não consiga administrar esse fato, é um propenso estudante desistente do curso.

\section{REFERÊNCIAS}

ABDON, Buenafe R.; NINOMIYA, Seishi; RAAB, Robert T. E-Learning in Higher Education Makes Its Debut in Cambodia: The Provincial Business Education Project. The International Review of Research in Open and Distance Learning. v.8. n.1. 2007.

ABRAEAD - Anuário Brasileiro Estatístico de Educação Aberta e a Distância. 3.ed. São Paulo: Instituto Monitor, 2007.

ANOHINA, A. Analysis of the terminology used in the field of virtual learning. Educational Technology \& Society, 8 , 91-102. (2005).

ARETIO, García Lorenzo. La educación a distancia: de la teoría a la práctica. Barcelona: Ariel, 2002.

Rendimiento académico y abandono en la educación superior a distancia. Madrid: UNED, 1987.

BIAZUS, Cleber Augusto. Sistema de fatores que influenciam o estudante a evadir-se dos cursos de graduação na UFSM e na UFSC: um estudo no curso de Ciências Contábeis. Florianópolis, 2004. Tese. (Doutorado em Engenharia de Produção). Universidade Federal de Santa Catarina.

CISLAGHI, Renato. Um modelo de sistema de gestão do conhecimento em um framework para a promoção da permanência discente no ensino de graduação. Florianópolis, 2008. 258 f. Tese (Doutorado) Programa de Pós-Graduação em Engenharia e Gestão do Conhecimento, UFSC, Florianópolis - SC.

FARIA, Lilian Maria de Oliveira Faria; ALCANTARA, V. M. ; GOIA, Carla Vasco. Índice e causas de evasão na Modalidade a Distância em Cursos de Graduação: estudo de caso. In: Universidad 2008 - VI Congresso Internacional de educação Superior, 2008, Havana. II taller Internacional, 2008.

FÁVERO, Rute Vera Maria; FRANCO, Sérgio Roberto Kieling. Um estudo sobre a permanência e a evasão na Educação a Distância. 2006. Disponível em < www.cinted.ufrgs.br/renote/dez2006/artigosrenote/25103.pdf> Acesso em mar. 2007.

FILKINS, Joseph W.; KEHOE, Laura E.; MCLAUGHLIN, Gerald W. Retention Research: Issues in Comparative Analysis. Annual Meeting of the Association for Institutional Research, Long Beach, CA, June 2001

V. $8 \mathrm{~N}^{\mathrm{o}} 3$, dezembro, 2010 
FOZDAR, Bharat Inder; KUMAR, Lalita S.; KANNAN, S. A Survey of Study on the Reasons Responsible for Student Dropout from the Bachelor of Science Programme at Indira Gandhi National Open University. The International Review of Research in Open and Distance Learning. v.7. n.3. 2006.

GARCIA, Paulo S. Redes Eletrônicas no Ensino de Ciências: Avaliação Pedagógica do Projeto Ecologia em São Caetano do Sul. Mackenzie SP - Dissertação de Mestrado, 1997. <http://rocha.ucpel.tche.br/RBIE/nr3-1998/Garcia03.htm>. Acessado em Abril 08.

LUDWIG-HARDMAN, Stacey; DUNLAP, Joanna C. Learner Support Services for Online Students: Scaffolding for success. The International Review of Research in Open and Distance Learning. v.4. n.1. 2003.

MAIA, Marta de Campos; MEIRELLES, Fernando de Souza. Tecnologias de informação e comunicação e os índices de evasão nos cursos a distância. 2005. Disponível em < http://www.abed.org.br/congresso2005/por/pdf/181tcc3.pdf> Acesso em fev. 2007.

MORGAN, Christopher K.; MCKENZIE, Anthony D. Is Enough Too Much? The dilemma for online distance learner supporters. The International Review of Research in Open and Distance Learning. v.4. n.1. 2003.

NEVADO, R.A. Estudo do Possível Piagetano em Ambiente de Aprendizagem Informatizado. São Paulo : Ática, 1997.

PACHECO, Andressa Sasaki Vasques. Evasão: análise da realidade do curso de graduação em Administração a distância da Universidade Federal de Santa Catarina. 2007. 136 f. Dissertação (Mestrado em Administração) - Programa de Pós-Graduação em Administração, Universidade Federal de Santa Catarina, Florianópolis, 2007.

PAULSEN, M. F. Online Education Systems: Discussion and Definition of Terms. 2002. Disponível em: (www.nettskolen.com/forskning/Definition\%20of\%20Terms .pdf). Acesso em junho 2008.

ROVAI, Alfred P. Building Sense of Community at a Distance. The International Review of Research in Open and Distance Learning. v.3. n.1. 2002.

RUMBLE, Greville. A gestão dos sistemas de ensino a distância. Brasília: Universidade de Brasília: UNESCO, 2003.

SIMONSON, Michael. In: BARBERÀ, Elena (coord). Educación abierta y a distancia. Barcelona: UOC, 2006.

TANNOUS, Kátia; ROPOLI, Edilene. Análise dos aspectos motivacionais relacionados à evasão e à aprovação em um curso de extensão. 2005. Disponível em < http://www.abed.org.br/congresso2005/por/pdf/152tcc5.pdf> Acesso em fev. 2007.

UNESCO. Aprendizagem aberta e a distância: perspectivas e considerações políticas educacionais. Florianópolis: Imprensa Universitária, UFSC, 1997. 